\title{
BMJ Open Patient and healthcare perspectives on the importance and efficacy of addressing spiritual issues within an interdisciplinary bone marrow transplant clinic: a qualitative study
}

\author{
Shane Sinclair, ${ }^{1}$ Shelagh McConnell, ${ }^{1}$ Shelley Raffin Bouchal, ${ }^{1}$ Naree Ager, ${ }^{2}$ \\ Reanne Booker, ${ }^{2}$ Bert Enns, ${ }^{2}$ Tak Fung $^{3}$
}

To cite: Sinclair $S$, McConnell S, Raffin Bouchal S, et al. Patient and healthcare perspectives on the importance and efficacy of addressing spiritual issues within an interdisciplinary bone marrow transplant clinic: a qualitative study. BMJ Open 2015;5:e009392.

doi:10.1136/bmjopen-2015009392

- Prepublication history for this paper is available online. To view these files please visit the journal online (http://dx.doi.org/10.1136/ bmjopen-2015-009392).

Received 15 July 2015 Revised 20 October 2015 Accepted 23 October 2015

CrossMark

\footnotetext{
${ }^{1}$ Faculty of Nursing, University of Calgary, Calgary, Alberta, Canada ${ }^{2}$ Alberta Health Services, Cancer Control, Tom Baker Cancer Centre, Calgary, Alberta, Canada

${ }^{3}$ Research Consulting Services, Information Technologies, University of Calgary, Calgary, Alberta, Canada
}

Correspondence to Dr Shane Sinclair; sinclair@ucalgary.ca

\section{ABSTRACT}

Objectives: The purpose of this study was to use a qualitative approach to better understand the importance and efficacy of addressing spiritual issues within an interdisciplinary bone marrow transplant clinic from the perspectives of patients and healthcare providers.

Setting: Participants were recruited from the bone marrow transplant clinic of a large urban outpatient cancer care centre in western Canada.

Participants: Focus groups were conducted with patients $(n=7)$ and healthcare providers $(n=9)$ to explore the importance of addressing spiritual issues across the treatment trajectory and to identify factors associated with effectively addressing these needs.

Results: Data were analysed using the qualitative approach of latent content analysis. Addressing spiritual issues was understood by patients and healthcare providers, as a core, yet under addressed, component of comprehensive care. Both sets of participants felt that addressing basic spiritual issues was the responsibility of all members of the interdisciplinary team, while recognising the need for specialised and embedded support from a spiritual care professional. While healthcare providers felt that the impact of the illness and treatment had a negative effect on patients' spiritual wellbeing, patients felt the opposite. Skills, challenges, key time points and clinical indicators associated with addressing spiritual issues were identified.

Conclusions: Despite a number of conceptual and clinical challenges associated with addressing spiritual issues patients and their healthcare providers emphasised the importance of an integrated approach whereby basic spiritual issues are addressed by members of the interdisciplinary team and by an embedded spiritual care professional, who in addition also provides specialised support. The identification of clinical issues associated with addressing spiritual needs provides healthcare providers with clinical guidance on how to better integrate this aspect of care into their clinical practice, while also identifying acute incidences when a more targeted and specialised approach may be of benefit.

\section{Strengths and limitations of this study}

- The impact of disease and treatment on patients spiritual well-being was perceived by healthcare providers as largely negative, while the majority of patients felt it had a positive impact, on spiritual well-being.

- While patients struggled to conceptualise spiritual well-being and their healthcare providers were challenged in addressing spiritual issues, both cohorts felt the ambiguity and inadequacy related to this care domain did not preclude healthcare providers from broaching the topic.

- Addressing basic spiritual issues was understood as a function of all team members, with the need for specialised, dedicated and embedded support from a spiritual care professional in order to address issues in an ongoing manner and in accordance with key time points and clinical indicators.

- Our small sample size limits the generalisability of our findings as the importance of spiritual well-being and practice recommendations were based on retrospective accounts and may vary with age, gender, symptomology, spiritualorientation and culture.

- Recommendations, barriers and enablers for addressing spiritual issues by members of the interdisciplinary team and spiritual care professionals are provided.

\section{INTRODUCTION}

Patients undergoing a bone marrow transplant (BMT) experience significant physical, psychosocial and spiritual issues affecting their well-being across the illness trajectory. An emerging body of literature demonstrates the significant impact that the disease and treatment has on various facets of BMT patients' quality of life. ${ }^{1-13}$ Spiritual well- 
being, alongside physical, psychological and social wellbeing is a recognised dimension of quality of life. ${ }^{4} 71214$ While preliminary evidence suggests that spiritual issues are important and common among BMT populations, empirical research has been limited and largely confined to opinion papers, theoretical discussions and case studies. ${ }^{15-17}$ As a result, while the importance of addressing aspects of spiritual well-being is increasingly recognised as a core component of integrated cancer care within this population, a corresponding evidence base investigating the clinical relevance and delivery of spiritual care is under studied in comparison to other dimensions of health within this population. ${ }^{145791218}$

Upon conducting a literature search of major healthcare databases, ${ }^{\mathrm{i}}$ a small number of studies were identified addressing issues related to spiritual well-being within a BMT population. Studies have demonstrated that aspects of spiritual well-being positively impact patient coping, survival, meaning in life, and posttraumatic growth, while simultaneously mitigating against spiritual and psychosocial distress. ${ }^{4} 12{ }^{19}$ In a large descriptive study $(n=159)$ using repeated measures before and after haematopoietic stem-cell transplantation ( $t=30,60,90$ and 180 days), Sirilla and Overcash ${ }^{18}$ reported that faith, prayer and spiritual healing were the most utilised alternative support resources identified by patients, a finding that is consistent across cancer groups. ${ }^{20}$ Evidence also suggests that spiritual well-being has a positive impact on aspects of psychosocial distress including reduced depression, ${ }^{18}$ while also enhancing health outcomes such as survival rates. ${ }^{21}$ Andrykowski et $a l^{1}$ investigated health related quality of life and spiritual well-being in long-term adult survivors $(\mathrm{n}=662$, avg. 7 years post-transplant) of haematopoietic stem cell transplants utilising the Post-traumatic Growth Inventory (PTGI) and the Functional Assessment of Chronic Illness Therapy-Spiritual Well-Being Scale (FACIT-Sp). The authors reported that BMT survivors had lower overall quality of life than the healthy comparison group, higher levels of psychological and interpersonal growth, with differences being sustained over time. The same study reported that survivors had slightly poorer spiritual well-being than the healthy comparison group narrowly meeting criterion for statistical significance $(\mathrm{p}=0.054)$. Owing to this finding and conceptual ambiguity associated with the concept of spirituality, the authors recommended that future research in this area is needed. ${ }^{1}$ While spirituality seemed to have a largely positive effect on quality of life, King et $a t^{22}$ reported that $18 \%$ of patients with BMT experience religious/spiritual struggle, highlighting the need for routine screening and documentation, as a secondary chart audit indicated that none of these issues were recorded within

${ }^{\mathrm{i}}$ Databases included CINAHL, Pubmed, and Medline from January 1994 to October 2014. Search terms included: spirituality, religion, bone marrow transplant, and cancer. the social worker's intake assessment. ${ }^{22}$ In order to address these gaps, we conducted focus groups to elicit patient and healthcare providers' perspectives on: (1) the importance of addressing spiritual issues across the BMT treatment trajectory and; (2) issues associated with effectively addressing spiritual needs within an interdisciplinary outpatient bone marrow transplant clinic. In this study we define spirituality as "an individual's beliefs, values, behaviours and experiences related to ultimate meaning" [ref. 23 pp.260].

\section{METHODS}

\section{Study population and setting}

Participants (patients and healthcare providers), were recruited from a large urban outpatient cancer care centre in western Canada. The centre provides treatment for patients with various types and stages of cancer extending into survivorship and palliative care. The bone marrow transplant clinic operates in a dedicated treatment area, providing care 5 days a week to patients at various points along the treatment trajectory. The frequency of individual patient visits ranges from daily, weekly, monthly or yearly visits depending on the patient's health status and proximity to date of transplant, with fewer visits occurring over time. An interdisciplinary care team consisting of a nurse practitioner, dietician, pharmacist, spiritual care professional, social worker, psychologist, registered nurses, and oncologists, provides supports to patients and their families. A convenience sample of consenting patients and healthcare providers meeting inclusion criteria was recruited over 2 months, with patients being informed about the study by clinic staff and healthcare providers being informed through an informal in-service. The inclusion criteria for patient participants consisted of: being a minimum of 18 years of age; being able to read and speak English, being a registered patient within the bone marrow transplant clinic; no demonstrated evidence of dementia/delirium; and ability to provide informed written consent. The inclusion criteria for healthcare provider participants included, being a healthcare provider working within the BMT clinic, able to read and speak English, and able to provide informed written consent. Demographic data and aspects of participant spirituality were collected to determine the composition of patient and healthcare provider focus groups (tables 1 and 2).

\section{Recruitment procedure and data collection}

The Conjoint Health Research Ethics Board at the University of Calgary approved the study and permission to formally access patients and clinicians was granted from the medical leader and clinic manager. Participants in this study were a subset of a larger crosssectional study of pre and post-transplant bone marrow therapy patients $(n=100)$ investigating the impact of the disease and treatment on aspects of spiritual and 
Table 1 Patient demographics

\section{Demographic information (patients)}

\begin{tabular}{|c|c|}
\hline Mean age (years) & $\begin{array}{l}49.6 \\
\text { (range: 24-69) }\end{array}$ \\
\hline Men & 3 \\
\hline Women & 4 \\
\hline $\begin{array}{l}\text { Mean days from transplant to } \\
\text { interview }\end{array}$ & $\begin{array}{l}925.3 \\
\text { (range: } 27-1706)\end{array}$ \\
\hline \multicolumn{2}{|l|}{ Highest education level attained } \\
\hline $\begin{array}{l}\text { Some university/college/technical } \\
\text { School }\end{array}$ & 3 \\
\hline $\begin{array}{l}\text { University/college/technical school- } \\
\text { completed }\end{array}$ & 3 \\
\hline Postgraduate university-completed & 1 \\
\hline \multicolumn{2}{|l|}{ Religious affiliation } \\
\hline Protestant & 4 \\
\hline Roman catholic & 1 \\
\hline None & 1 \\
\hline \multicolumn{2}{|l|}{ Religiousness } \\
\hline Very religious & 1 \\
\hline Fairly religious & 2 \\
\hline Not too religious & 2 \\
\hline Not religious at all & 2 \\
\hline \multicolumn{2}{|l|}{ Spirituality } \\
\hline Very spiritual & 2 \\
\hline Fairly spiritual & 4 \\
\hline Not too spiritual & 1 \\
\hline \multicolumn{2}{|l|}{ Religious and spiritual status } \\
\hline Spiritual and religious & 4 \\
\hline Spiritual but not religious & 3 \\
\hline Neither religious or spiritual & 0 \\
\hline \multicolumn{2}{|c|}{ Interactions with the spiritual care professional/chaplain } \\
\hline Met frequently during treatment & 1 \\
\hline $\begin{array}{l}\text { Met on a number of occasions } \\
\text { during treatment }\end{array}$ & 2 \\
\hline $\begin{array}{l}\text { Met a few times after admission to } \\
\text { clinic }\end{array}$ & 1 \\
\hline Met once after admission to clinic & 2 \\
\hline Not met but open to meeting & 1 \\
\hline
\end{tabular}

psychosocial well-being across the illness trajectory (diagnosis/pretreatment to survivorship/palliative care) that is currently under review. In addition to being administered a battery of measures, participants in this larger study were administered a demographic questionnaire in which they were asked whether they would be interested in participating in a focus group. Thirty-eight patient participants indicated initial interest in participating in one of the two patient focus groups. Of those, 10 declined to participate due to scheduling conflicts, 10 were unreachable by phone, 5 did not return voice mails, 1 was admitted as an inpatient, 1 was no longer interested, and 4 died before the focus groups were conducted. Two patient focus groups containing a total of seven patients were conducted (table 1). A convenience sample of nine healthcare providers were recruited via a sign-up poster in the clinic, following a brief in-service informing clinic staff of the study. Two healthcare
Table 2 Clinician demographics

Demographic information (clinicians)

Mean age (years) 37.7

Men 1

Women

Years working with BMT patients(years) 8.3

Profession

Registered nurse

Physician 2

Pharmacist 1

Social worker 1

Psychologist 1

Highest education level attained

University/college/technical school_ 4

completed

Postgraduate university-completed 5

Religiousness

Fairly religious

Not too religious 3

Not religious at all $\quad 5$

Spirituality

Very spiritual

Fairly spiritual 3

Not too spiritual 3

Religious and spiritual status

Spiritual and religious

Neither religious or spiritual 2

BMT, bone marrow transplant.

provider focus groups, representing a variety of disciplines were conducted (table 2).

Focus groups were held in a private setting within the cancer centre between June and August 2013. A list of semistructured guiding questions was devised by the research team based on their clinical experience within this population and a review of the literature (box 1).

Focus groups were conducted by a seasoned qualitative interviewer. Field notes were recorded by another member of the research team during each focus group to capture contextual and non-verbal features. Interviews were audio recorded and transcribed verbatim using pseudonyms to protect participant anonymity (patients A-G; clinicians A-I). Data integrity between audio files and transcripts was assured through line-by-line verification of the transcripts and the audio recording, by the transcriptionist as well as a member of the research team. The focus groups ranged from one to one and a half hours, resulting in four transcripts varying in length from 16 to 23 double-spaced pages each.

\section{Method of analysis}

Data analysis started following the completion of all four focus groups. Data, in the form of transcripts and field notes, were analysed over a 4-month period using latent content analysis ${ }^{24}$ and the constant 


\section{Box 1 Interview/focus group questions}

\section{Patients:}

1. Spiritual well-being means different things to different people, can you please tell us what spiritual well-being means to you?

2. What sources of spiritual support did you have prior to coming to the bone marrow transplant (BMT) clinic?

3. How has your cancer diagnosis and treatment impacted your sense (based on the definition you provided) of spiritual well-being?

4. Compared to your other care needs, how important do you feel it is to have issues related to your spiritual well-being addressed?

5. What has contributed to your spiritual well-being during your treatment (at diagnosis, initial treatment and onward)? What has positively contributed to your spiritual well-being? What experiences diminish your sense of spiritual well-being?

6. Are there points in your cancer journey where you anticipate needing spiritual support (pre-transplant) or felt spiritual support was most needed (post-transplant)? Least needed? Can you describe why or why not?

7. How has the availability of spiritual supports affected your illness experience and your perceptions about this service?

8. Based on your experience (whether as an inpatient or outpatient) what recommendations would you make to enhance the delivery of spiritual care to patients with BMT?

9. Are there others ways that you feel the cancer centre could support your spiritual well-being? (designation and design of spaces, gardens, integration of the arts, music, aesthetics/environmental considerations, etc...)?

Clinicians:

1. Spiritual well-being means different things to different people, can you please tell us what spiritual well-being means to you?

2. Based on your clinical experience, what impact do you feel treatment (diagnosis, initial treatment and onward) has on BMT patients' spiritual well-being?

3. Compared to patients other care needs, how important do you feel it is to have issues related to your spiritual well-being addressed?

4. Based on your clinical experience, what interventions (clinical or non-clinical) do you feel most effectively contribute to patient's spiritual well-being? What diminishes patient's spiritual well-being?

5. Are there points in the patient journey (inpatient and/or outpatient, newly diagnosed/treatment phase, etc...) where you feel spiritual support is most needed? Least needed? Can you describe why or why not?

6. How do you feel the availability of spiritual supports has affected patients' illness experience and perception of this service? How has the availability of spiritual support affected your work with patients and workplace wellness?

7. Based on your experience what recommendations would you make to enhance the delivery of spiritual care to patients with BMT (inpatient and outpatient)?

8. Are there others ways that you feel the cancer centre could address your own and patients' spiritual well-being? (designation and design of spaces, gardens, integration of the arts, music, aesthetics/environmental considerations)?

comparative technique whereby subsequent codes within and across transcripts are compared and contrasted with previous codes. ${ }^{26}$ The constant comparative technique is particularly helpful in studies investigating the subjective experience, values and beliefs of participants as it assures that data analysis is representative of the sample, rather than individual accounts or investigators interpretations in order to fit their apriori theory. ${ }^{26}$ Latent content analysis was considered an appropriate study method due to its focus on the underlying meaning of content, ${ }^{27}$ which was congruent with the subjective and meaning-based nature of the research topic. Members of the research team conducted the data analysis, first by independently coding each transcript line-by-line using an open coding approach whereby words and phrases are highlighted and initial codes (units of meaning) are recorded in the margins of the transcript. ${ }^{28}$ The research team held two analysis meetings where a secondary line-by-line approach of analysis was employed whereby independent codes and emerging themes were continuously compared and discussed until consensus was reached for all codes. The research team met a third time to cluster related themes and subthemes from both sets of focus groups into overarching categories or families of themes through an inductive and iterative process until consensus was reached.

\section{RESULTS}

After data from the patient focus groups and healthcare provider focus groups had been analysed and coded, four categories containing corresponding themes and subthemes emerged from the data, with variance occurring within and between the two participant groupsproducing a fulsome and holistic account of the area of interest. The four major categories that emerged from the qualitative analysis were: (1) addressing spiritual wellbeing, (2) impact of illness on spiritual well-being, (3) when to address spiritual issues, and (4) enhancing spiritual well-being in the clinical setting. These categories, and corresponding patient and healthcare provider exemplars, provide insight into the importance of spiritual well-being within a bone marrow transplant population and provide guidance on how to effectively address spiritual issues within an interdisciplinary bone marrow transplant clinic. The results suggest that issues related to spiritual well-being are an important component of comprehensive care that is ideally addressed at key clinical time points and on a routine basis-especially in the presence of multifactorial suffering. Basic spiritual care can be provided by all members of the interdisciplinary team, in addition to specialised spiritual care provided by a dedicated spiritual care professional, ${ }^{29}$ ameliorating patient distress and potentially benefitting healthcare providers workplace well-being in the process. 


\section{Addressing spiritual well-being}

Issues related to addressing spiritual well-being in the bone marrow transplant trajectory were explored within all four focus groups. Both healthcare providers and patients were unequivocal in their belief that addressing spiritual well-being was an important component of care across at all stages of their illness trajectory (diagnosis/pre-transplant work-up-survivorship/palliative care). Specifically, patients and healthcare providers shared their personal understandings of spirituality, noting challenges in doing so, due to the ineffable nature of the concept. In addition, participant groups spoke of bedside skills utilised in addressing spiritual issues, associated challenges, and the need for a more integrated approach. In addition to these shared themes, healthcare providers also identified scope of practice as a further challenge in addressing issues associated with spiritual well-being within the interdisciplinary clinic.

\section{Conceptualising spiritual well-being}

Spiritual well-being was identified by participants as the ability to live in alignment with ones values and priorities; to have a sense of ultimate purpose in life; and to foster a sense of meaning, each of which provided a sense of inner peace in times of uncertainty.

Clinician D: [The patient] understood what was important to him in life and he had met those goals and those values and you could tell from how he had raised his children that he saw his children were living with those values and so he was at peace with that, and I think, of anyone that I've ever seen that I would say was spiritually well; he was well.

Patient D: Well for me, if I may, it's really about feeling a connection, you know... that I'm practicing what I believe in and staying true to those values and making sure that I'm living the way I want to be living through my faith and the beliefs.

\section{Bedside skills}

Bedside skills were identified by participants as those skills that are essential in addressing spiritual issues. Patients and healthcare providers identified a number of qualities that healthcare providers who were skilled in addressing spiritual issues possessed. These included approaching the topic of spirituality with sensitivity, listening intently for aspects of patients' spirituality, engaging in meaning-based conversations, not spiritualising issues, and being present. Along with these skills, patients specifically identified a 'non-agenda' approach or a patient driven approach as a distinguishing feature of addressing spiritual issues in an effective manner.

Patient F: I found it very good to speak about it, well a lot of people, but in particular with Dominic [part-time spiritual care professional], just simply because it was just someone to talk to with, there was no... it wasn't directed, it was just a conversation so if you had something going on in your head you could have that conversation.

Clinician $\mathrm{H}$ : And to be present, you know? Not to be doing, like sometimes they don't need you doing, you know, even though that's what my task is at that time, it's just to stop that and then, and that's why I say, you know, I think that we can't block and say, "Okay, you know, Patient X you get your thirty-five minutes and you know, you get your twenty minutes of, you know, post-transplant teaching."

\section{Challenges to addressing spiritual issues}

Addressing spiritual issues were fraught with conceptual challenges according to patients and healthcare providers, with healthcare providers identifying additional professional and personal issues inhibiting their ability to effectively address spiritual issues within a clinical setting. An inherent challenge identified by patients and healthcare providers was the ephemeral nature of spirituality, as participants found it challenging to convey their understanding of spirituality with words. A second challenge identified, was a tendency to conflate spirituality and religion. Healthcare providers recalled attempts to address a patient's spiritual issues which were misinterpreted as religious care, while patients identified incidences of healthcare providers whose desire to address spiritual issues seemed to be motivated from their own personal convictions. The fear of offending patients or not being sensitive to patients' cultural or spiritual beliefs, was described by healthcare providers as potent inhibitor to addressing spiritual issues. A final challenge identified by healthcare providers was a lack of education and clinical training in how to effectively broach spiritual issues within routine clinical communication.

Clinician A: I think my biggest problem is how to approach [patients] about that, when to approach them about that because, I mean, we've been trained to be quite respectful to people, [of] all different backgrounds, all different cultures and it's, if, you know, growing up in one particular religious household makes me unfamiliar about the others, so I don't feel comfortable addressing it to, without any kind of background. The last thing I want to do is offend a patient and I think even, that's my biggest fear, is offending somebody.

Clinician C: ...we need to learn how to frame that, you know, we need to learn, how to say what spiritual care is, you know, what the services are that they can use and that it's not religion, that, can we say it in a way where religion doesn't come up?

Patient E: I felt bad for her [healthcare provider inquiring about patients spiritual issues] because she felt bad, kind of was like, "Oh are you spiritual?" like as if she was going to get in trouble or offend me or something and, you know, even if I wasn't spiritual, it's okay, like it's a 
free country, everyone's entitled to say or not say or believe or not believe so. It was kind of nice for her to come at it from that angle, and yeah, because like, I know that it's sometimes, taboo...

A final healthcare provider challenge in addressing spiritual issues related to how to clinically screen and assess for spiritual issues.

Clinician A: [Patients] come in and they tell you a whole bunch of vague symptoms or, you know, they can't cope at work or they can't concentrate or something and they don't fit into a diagnosis or anything but there's obviously something unbalanced there and I think those are the people that we're missing.

\section{Scope of practice}

Healthcare providers identified issues related to clinical scope of practice as an additional challenge in addressing spiritual issues. The majority of healthcare providers felt that addressing basic spiritual issues fell within the scope of practice of a number of disciplines, while also recognising the need for a dedicated specialist whose scope of practice focused exclusively on spiritual issues, particularly when patients were experiencing acute or complex spiritual distress. Overlapping scopes of practice were not restricted to inherently spiritual issues, as healthcare providers recognised the role of spiritual care professionals in addressing psychosocial issues, noting that in many incidences these domains of care were intertwined. While acknowledging overlapping roles, healthcare providers identified the need to delineate clear criteria for referring patients to spiritual care professionals.

Clinician A: I think everyone can provide spiritual support, depends on who they are, doesn't matter what their profession is.

Clinician H: I think having the resources to call somebody... and have someone come is invaluable, really when we don't know where else to reach out to.

Patient C: I think it's a good option to have available to people... like I said earlier, I'm not really a religious person per se but I appreciate the intent behind, you know, when people offer things like that and I don't take offence to that. I had a patient care aide, I hadn't even met her... and there's this sort of timid knock on my door and she kind of comes in and she's all shy and, you know, in somewhat broken English, she asked me if it was okay if on her break, she could come in and say some prayers for me in her own language and I was really flattered and honored by that, you know... I hadn't even met [her], I didn't know who she was or anything and she just wanted to try and help me and the only way she knew how, and I thought that was just wonderful, you know, so I think things like that are great.

\section{The need for integrated and dedicated spiritual care}

Clinicians believed that all patients could benefit from a dedicated and integrated spiritual care professional within the BMT clinic in contrast to the consultation model that was currently employed. This recommendation was based primarily on their belief that patients' spiritual well-being was a prevalent aspect of their overall illness experience. In order to effectively address the spiritual issues of patients with BMT, participants felt that spiritual care needed to become a formalised and routine aspect of care, rather than an ancillary service that was utilised strictly on a consult basis.

Clinician C: [Spiritual care professionals] make a huge impact on our patients and it is very different to come in after they have been speaking with that person and there is a difference because Dominic [spiritual care professional] was in there two hours ago doing something and then they've been in there and there is a difference.

\section{Impact of illness on spiritual well-being}

The second category, impact of illness on spiritual wellbeing, refers to the effects that the illness and treatment had on patients' spiritual well-being. Healthcare provider focus group data primarily focused on the negative impact that they felt the disease and treatment had on patients. In contrast, while patients did identify aspects of spiritual struggle along the treatment trajectory, in retrospect they described their experience as a patient with BMT as having a largely positive impact on their spiritual well-being.

\section{Positive impacts of illness on spiritual well-being}

Patients identified a number of positive impacts that they felt the illness had on their spiritual well-being including: clarified life priorities, a greater sense of gratitude, and an enhanced appreciation for the little things in life. While healthcare providers did not identify a positive impact on patients' spiritual well-being, they did feel that that their own sense of spirituality was enhanced in accompanying patients through their health crisis, clarifying their own life priorities and enhancing their appreciation of life in the process.

Patient D: It really helped me put things back in perspective in terms of, you know, priorities, really looking to be grateful for everything.

Patient G: I know for a while after I got sick, I really lost my spirituality and you know why, I thought, "Why, why me?"... You know, but then after a while it came, it became very important to me...Yeah, and it still does. I have to believe things happen for a reason and you deal with it and believe that somebody out there is going to stay with you.

Clinician H: We're the blessed ones, with the people that we work with.

Negative impacts of illness on spiritual well-being

Healthcare providers identified three specific ways in which spiritual well-being was diminished. These ranged 
from the immediate impact associated with treatment burden, to the long-term impact associated with emotional issues and relational discord with loved ones, to existential issues such as a loss of purpose in life and redefining life roles.

Clinician A: We drop out of their lives fairly quickly [after treatment] but they're expected to go back to the way things were before and that's impossible. To have been through such a traumatic event, some of these people actually suffer from Post Traumatic Stress Disorder ... They can't get over what's happened to them, they can't accept that they are different and... families have broken up because of that, because the partners can't deal with it, because they can see them and well, you look well, things are going well, how come you can't go back to where you were before?

Clinician D: There's that partner dynamic kind of thing and that spirituality is often very much mute to a lot of partners, even when they're discrepant, they're still a blank between the two.

Clinician A: It's a huge test. It's not easy going through a bone marrow transplant. It's not easy going through this stuff, they get, before they get to the transplant, you know, this is kind of, it is, you are facing your mortality when patients are diagnosed with either leukemia or lymphoma and then heading to transplant and many of these patients are young, who've never had to do that before, just thinking about my two nineteen year-olds [patients] on the ward right now, I mean when you're nineteen you don't think of stuff like that.

\section{Routine and specific clinical time points for addressing spiritual issues}

Both patient and healthcare providers offered their perspective on when they felt spiritual issues should be optimally addressed over the course of their cancer journey. While some participants identified key time points within the disease trajectory (eg, at diagnosis, post-transplant, or at the end of life), others felt that addressing spiritual issues was best determined by clinical indicators (eg, prevalence of multifactorial suffering, disease progression, symptom burden). While there were specific junctures within the treatment trajectory when spiritual issues were particularly salient, participants also identified the necessity of an integrated and routine approach in order to develop the relational foundation on which more acute interventions could be effectively delivered.

\section{Key time points for addressing spiritual issues}

Three key time points or stages were identified by patient and healthcare providers where patients were felt to be particularly susceptible to spiritual distress: diagnosis, post-transplant, and survivorship.

Clinician G: No matter at what part of their journey they're at, it could be at the pre-part, it could be the middle part, it could be the end part, it could be the end of life part, but to really try and find what I can do to bring that peace to them

Patient D: So that March date, June 15th date [anniversary of their transplant], and... you know, they're not marked on the calendar, but it just kind of, you know, triggers some things...

\section{Clinical indicators}

A number of participants felt that clinical indicators were a preferred mechanism for determining optimal opportunities to address spiritual issues. In general, experiences of suffering were identified as incidences when attending to spiritual issues was most needed. In the context of the BMT trajectory this included prognostic changes, existential crisis and physical symptomology. A number of participants postulated that developing thresholds associated with these clinical indicators could serve as a mechanism for initiating a referral to a spiritual care professional.

Patient G: It was after the setback with the septicemia that really did me up and that's when I needed it, yeah, because I was very, very ill. I couldn't do anything, I was physically just done and that's when I needed it and that's when I got it.

Clinician A: I've had many people say, you know, without their spirituality or without their religious beliefs or whatever, they would not, they would never be able to get through it and people will say, "I don't know how you can get through this," you know, the power of prayer or whatever. I think when they're at their sickest, obviously, it's important.

\section{Routine and integrated spiritual care}

While there were specific incidences when participants felt that addressing spiritual issues was particularly beneficial, it did not preclude the need for a routine and integrated approach to spiritual care. Routine and impromptu visits by the spiritual care professional engendered a therapeutic relationship that could be drawn on in times of crisis. The importance of being readily available or rapidly responding to a spiritual or emotional crisis was also identified as a potential benefit to having an embedded spiritual care professional in the clinic, with patients and healthcare providers noting that the lack of a dedicated individual was an ongoing challenge.

Patient C: When Dominic and Thelma [part-time spiritual care professionals] would be doing a little 'impromptu wandering about'... you know it's a, "Hey, hi, how are you guys doing?" and you know, gauging and feeling, you know, how's that and you know, having a little sit down and chat and you know, it flows into wherever... and suddenly we're coming into go and do something and then we find out things because of that impromptu part of the puzzle. 
Clinician B: You know how you can go to Magic cuts and go get your haircut without an appointment, like it just might be my opinion, just to have somebody [from spiritual care] available, you know?

\section{Enhancing spiritual well-being in the clinical setting}

In addition to increased resources and more targeted interventions, participants, particularly patients, felt that spiritual well-being could be enhanced in practical ways through the creation of healing clinical spaces and centralised meditation/sacred spaces. Incorporating nature within the cancer centre, whether a flowering atrium or positioning treatment spaces beside windows, were ways that participants felt their spiritual well-being could be enhanced. Participants also felt that a centralised meditative or sacred space within the cancer centre could serve as a symbolic reminder of the importance of attending to one's spiritual health, while also serving as a place where patients and healthcare providers from diverse backgrounds could partake in spiritual practices and rituals.

Patient F: It would be fantastic to be able to sit in more of a garden setting, a little bit, because, just because the feeling of the life you get from flowers just is really, could really bring your spirits up.

Clinician F: Yeah, quiet, serene places where they can go and, music and inspiring, kind of, you know, calming, comfortable, where their needs are met. This is kind of a peaceful need.

Clinician H: Where they can engage in some of those informal or formal practices, I guess, more formal probably practices that, like meditation or prayer would be helpful.

\section{DISCUSSION}

This study provides insight into understanding and addressing issues related to spiritual well-being from the clinical experience of patients with bone marrow transplant and their healthcare providers. The ineffable nature of spirituality was a pre-eminent challenge, both in terms of articulating their views in the study and in relation to addressing spiritual issues in the clinical encounter, supporting the findings of previous studies and theoretical frameworks. ${ }^{23}{ }^{30}$ Despite these linguistic challenges, patients and healthcare providers were unequivocal in identifying spiritual well-being as an important, yet under addressed and under studied component of comprehensive care. Our qualitative results echo and add clinical narratives to Heyland et $a l^{31} 32$ multicenter quantitative studies of palliative care patients and their family caregivers who identified spiritual issues among patients' greatest and most unmet needs. These results are further reflected in other cancer populations, as studies report that $78 \%$ of patients with cancer identify spirituality as an important need, ${ }^{33}$ with $75 \%$ of cancer inpatients reporting that they felt their spiritual needs were not addressed. ${ }^{34}$ Spiritual needs within various patient populations include religious rituals, being at peace with God, finding hope, enhancing interpersonal connections, life review, maintain meaning in life and alleviating spiritual distress. ${ }^{35-38}$

Our study identified a number of challenges associated with addressing spiritual issues within an outpatient bone marrow transplant clinic. While healthcare providers and patients felt that addressing spiritual issues fell within the scope of practice of a number of interdisciplinary team members, one of the greatest inhibitors identified by both participant groups seemed to be healthcare providers themselves. As has been reported in a number of studies, ${ }^{39-41}$ there remains a significant theory-practice gap, as translating these competencies and skills into clinical practice in a sensitive manner was a considerable barrier identified by healthcare providers. In contrast to healthcare provider participants' perceptions and Mansfield et al $\mathrm{s}^{42}$ findings that patients are uncomfortable discussing religious and spiritual issues with their healthcare providers, patients in this study reported a desire to have these issues addressed by their healthcare team. This seems to suggest that the fear of offending patients in broaching these issues may not be as detrimental as healthcare providers think. Research investigating factors associated with this practice gap identifies a lack of education and training as one the most cited reasons for not addressing these issues, ${ }^{42}{ }^{43}$ imploring healthcare faculties and continuing educational programmes to integrate training on effectively addressing spiritual issues into their curriculum. Both participant groups felt that attending to spiritual needs required a dedicated, embedded and readily available spiritual care professional in contrast to the limited consultant-based approach that was currently offered. Healthcare providers also identified the need for greater clarity in how to communicate the role of the spiritual care professional and when to refer patients to the service, especially in relation to determining whether the spiritual care professional or another member of the supportive care team was best suited to provide psychosocial support. ${ }^{23}$ The largely bedsidebased practice of spiritual care professionals, in contrast to an one-on-one office-based approach of other members of the psychosocial care team, was seen by patients and healthcare providers as a unique and particularly beneficial aspect of the clinic's spiritual care professionals practice-often affecting patients' spiritual well-being and healthcare providers' workplace wellbeing in the process.

In addition to these clinical insights and the need for routine spiritual support, healthcare providers and patients identified three stages within the disease trajectory when spiritual issues were particularly important to address: diagnosis, post-transplant, and survivorship. A significant and recognised component of spirituality is its function as a meaning-making framework. ${ }^{45}$ In contrast to their busy clinic schedules and exhausting 
physical procedures pre- and post-transplant, healthcare providers identified survivorship as a time when patients try to make sense and meaning of their illness experience and their life's purpose. Unfortunately, studies have demonstrated that spiritual well-being within this population decreases over time, ${ }^{1}$ which suggests the need for ongoing spiritual support as clinic visits and physical symptoms diminish.

Although study participants, representing perspectives across the cancer trajectory and from both sides of the bedrail, did not explicitly identify end-of-life as a key time point for addressing spiritual issues, it seemed that issues related to suffering and facing one's mortality were prevalent and implicit issues. As such, suffering and being confronted by issues of mortality seemed to be a particularly ardent elicitor of spirituality, irrespective of impending physical death. A qualitative study investigating the spiritual needs of combat veterans at the end of life, reported that many of the study participants actually felt that their military experience enhanced their sense of spirituality. ${ }^{36}$ The theory of mortality salience ${ }^{46}$ suggests that a corollary affect to facing one's mortality is increased reflection and identification with one's beliefs and worldview, including an increased sense of meaning. Patients and healthcare providers in this study, while acknowledging considerable psychosocial and spiritual distress and symptom burden, described the cumulative impact of these issues as having a largely positive effect on their spiritual wellbeing. The positive effect between attending to suffering and healthcare providers spirituality was reported in two recent studies of palliative care professionals, ${ }^{47} 48$ suggesting that healthcare providers may find themselves reflecting on the same questions that their patients are reflecting on. ${ }^{49}$ In the same manner that trauma can function as a catalyst to psychological growth, this study suggests that mortality may function as a catalyst for spiritual growth.

\section{LIMITATIONS}

There are a number of limitations to this exploratory study, including the generalisability of our findings due to our small sample size. As such, future research with a larger and more diverse sample is needed to confirm our findings, as the importance afforded to spiritual well-being and practice recommendations, may vary with age, gender, and especially culture. ${ }^{50}$ Second, while being a fairly spiritually heterogeneous group (tables 1 and 2), by utilising convenience sampling for both study cohorts, a potential sample bias may have been introduced, namely that a disproportionate number of spiritually-minded and motivated individuals signed up for the focus group that is not reflective of the general patient and healthcare provider population. Specifically, caution should be exercised in assuming that the importance attributed to addressing spiritual issues and patients' desires and comfort in communicating about spiritual issues is shared by all patients. Furthermore, the retrospective accounts of a largely asymptomatic patient group, who were well enough to make an additional visit to the cancer centre to attend the $1.5 \mathrm{~h}$ focus group may not reflect the fluctuating nature of the disease and may have inadvertently excluded patients experiencing spiritual distress.

\section{CONCLUSION}

In this study, we assessed the importance and relevance of spiritual care within a BMT outpatient clinic, from patients' and healthcare providers' perspectives to determine its meaning across the illness trajectory. Results indicate that spiritual issues are a significant component of the patient experience, which when addressed may enhance patient well-being and satisfaction with care. Both sets of participants emphasised the need to address spiritual well-being in a routine and fluid manner. While initiating and engaging in conversations about spirituality sometimes elicited fear on the part of healthcare providers, it was deemed a necessary aspect of comprehensive care that patients' wanted addressed. Interestingly, the impact of illness, personally and empathetically, seemed to enhance patients and healthcare providers own sense of spiritual well-being; as being in close proximity to mortality evoked a deepened appreciation for life not only for patients, but for healthcare providers.

Contributors SS, BE, SRB, and NA conceptualised the study. SS, SM, SRB, $\mathrm{RB}$, and TF were involved in designing the study and developing the methods. SS, SRB, TF and NA obtained funding. SS provided overall direction for the study. SS, SM, SRB read the transcripts, analysed data, and developed a coding schema. All authors contributed to the interpretation of the analysis, critically revised the manuscript and approved the final draft.

Funding This work was supported by the Alberta Cancer Foundation (grant number 25971).

Competing interests None declared.

Ethics approval The University of Calgary Conjoint Health Research Ethics Board.

Provenance and peer review Not commissioned; externally peer reviewed.

Data sharing statement No additional data are available.

Open Access This is an Open Access article distributed in accordance with the Creative Commons Attribution Non Commercial (CC BY-NC 4.0) license, which permits others to distribute, remix, adapt, build upon this work noncommercially, and license their derivative works on different terms, provided the original work is properly cited and the use is non-commercial. See: http:// creativecommons.org/licenses/by-nc/4.0/

\section{REFERENCES}

1. Andrykowski MA, Bishop MM, Hahn EA, et al. Long-term health-related quality of life, growth, and spiritual well-being after hematopoietic stem-cell transplantation. J Clin Oncol 2005;23: 599-608.

2. Belec RH. Quality of life: perceptions of long-term survivors of bone marrow transplantation. Oncol Nurs Forum 1991;19:31-7.

3. Bevans M, Marden S, Leidy N, et al. Health-related quality of life in patients receiving reduced-intensity conditioning allogeneic 
hematopoietic stem cell transplantation. Bone Marrow Transplant 2006;38:101-9.

4. Ferrell B, Grant M, Schmidt GM, et al. The meaning of quality of life for bone marrow transplant survivors Part 1. The impact of bone marrow transplant on quality of life. Cancer Nurs 1992;15:153-60.

5. Fromm K, Andrykowski MA, Hunt J. Positive and negative psychosocial sequelae of bone marrow transplantation: implications for quality of life assessment. J Behav Med 1996;19:221-40.

6. Gaston-Johansson F, Foxall M. Psychological correlates of quality of life across the autologous bone marrow transplant experience. Cancer Nurs 1996;19:170-6.

7. Grant M, Ferrell B, Schmidt G, et al. Measurement of quality of life in bone marrow transplantation survivors. Qual Life Res 1992;1:375-84.

8. Haberman MR. Psychosocial aspects of bone marrow transplantation. Semin Oncol Nurs 1988;4:55-9.

9. Saleh US, Brockopp DY. Quality of life one year following bone marrow transplantation: psychometric evaluation of the quality of life in bone marrow transplant survivors tool. Oncol Nurs Forum 2001;28:1457-64

10. Pidala J, Anasetti C, Jim H. Quality of life after allogeneic hematopoietic cell transplantation. Blood 2009;114:7-19.

11. Wettergren L, Sprangers $M$, Björkholm $M$, et al. Quality of life before and one year following stem cell transplantation using an individualized and a standardized instrument. Psychooncology 2008;17:338-46.

12. Whedon M, Ferrell BR. Quality of life in adult bone marrow transplant patients: beyond the first year. Semin Oncol Nurs 1994;10:42-57.

13. Haberman M, Bush N, Young K, et al. Quality of life of adult long-term survivors of bone marrow transplantation: a qualitative analysis of narrative data. Oncol Nurs Forum 1992;20:1545-53.

14. Farsi Z, Dehghan Nayeri N, Negarandeh R. Coping strategies of adults with leukemia undergoing hematopoietic stem cell transplantation in Iran: a qualitative study. Nurs Health Sci 2010;12:485-92.

15. King D, Crisp J. Case discussion: do not neglect the spiritual history. South Med J 2007;100:426.

16. Berger JA. Living the discipline on a stem cell transplant unit: spiritual care outcomes among bone marrow transplant survivors. $J$ Health Care Chaplain 2001;11:83-93.

17. Cohen M, Headley J, Sherwood G. Spirituality and bone marrow transplantation: when faith is stronger than fear. Int $J$ Hum Caring 2000;4:40-6.

18. Sirilla J, Overcash J. Quality of life (QOL), supportive care, and spirituality in hematopoietic stem cell transplant (HSCT) patients. Support Care Cancer 2013;21:1137-44.

19. Widows MR, Jacobsen PB, Booth-Jones M, et al. Predictors of posttraumatic growth following bone marrow transplantation for cancer. Health Psychol 2005;24:266-73.

20. Zaza C, Sellick SM, Hillier LM. Coping with cancer: what do patients do. J Psychosoc Oncol 2005;23:55-73.

21. Pereira DB, Christian LM, Patidar S, et al. Spiritual absence and 1 -year mortality after hematopoietic stem cell transplant. Bio Blood Marrow Transplant 2010;16:1171-9.

22. King SD, Fitchett G, Berry DL. Screening for religious/spiritual struggle in blood and marrow transplant patients. Support Care Cancer 2013;21:993-1001.

23. Sinclair S, Chochinov HM. Communicating with patients about existential and spiritual issues: SACR-D work. Prog Palliat Care 2012;20:72-8.

24. Field $\mathrm{P}$, Morse JM. Nursing research: the application of qualitative research methods. London, UK: Croom Helm, 1985.

25. Fox DJ. Fundamentals of research in nursing. 4th edn. Toronto, ON, Canada: McGraw-Hill, 1982

26. Glaser BG, Strauss AL. The discovery of grounded theory: strategies for qualitative research. New York, NY: Aldine, 1967.

27. Hsieh HF, Shannon S. Three approaches to qualitative content analysis. Qual Health Res 2005;15:1277-88.

28. Corbin JM. Basics of qualitative research: techniques and procedures for developing grounded theory. Thousand Oaks, CA: SAGE, 2015.

29. Sinclair S, Chochinov HM. The role of chaplains within oncology interdisciplinary teams. Curr Opin Support Palliat Care 2012, 6:259-68.
30. Sinclair S, Raffin S, Pereira J, et al. Collective soul: the spirituality of an interdisciplinary palliative care team. Palliat Support Care 2006;4:13-24

31. Heyland DK, Dodek P, Rocker G, et al. What matters most in end-of-life care: perceptions of seriously ill patients and their family members. Can Med Assoc J 2006;174:627-33.

32. Heyland DK, Cook DJ, Rocker GM, et al. Defining priorities for improving end-of-life care in Canada. Can Med Assoc J 2010;182: E747-E52.

33. Alcorn SR, Balboni MJ, Prigerson HG, et al. "If God wanted me yesterday, I wouldn't be here today": religious and spiritual themes in patients' experiences of advanced cancer. J Palliat Med 2010;13: $581-8$

34. Balboni TA, Vanderwerker LC, Block SD, et al. Religiousness and spiritual support among advanced cancer patients and associations with end-of-life treatment preferences and quality of life. J Clin Oncol 2007;25:555-60.

35. Steinhauser KE, Christakis NA, Clipp EC, et al. Factors considered important at the end of life by patients, family, physicians, and other care providers. JAMA 2000;284:2476-82.

36. Chang BH, Stein N, Trevino $\mathrm{K}$, et al. Spiritual needs and spiritual care for veterans at the end of life and their families. Am J Hosp Palliat Care 2012;29:610-7.

37. Moadel A, Morgan C, Fatone A, et al. Seeking meaning and hope: self-reported spiritual and existential needs among an ethnicallydiverse cancer patient population. PsychoOncology 1999;8: 378-85.

38. Hui D, de la Cruz M, Thorney S, et al. The frequency and correlates of spiritual distress among patients with advanced cancer admitted to an acute palliative care unit. Am J Hosp Palliat Care 2011;28:264-70.

39. Sinclair S, Raffin Bouchal S, Chochinov $\mathrm{H}$, et al. Spiritual care: how to do it. BMJ Support Palliat Care 2012;2:319-27.

40. Astrow $A B$, Wexler $A$, Texeira $K$, et al. Is failure to meet spiritual needs associated with cancer patients' perceptions of quality of care and their satisfaction with care? J Clin Oncol 2007;25:5753-7.

41. Kristeller JL, Sheedy Zumbrun C, Schilling RF. 'I would if I could': how oncologists and oncology nurses address spiritual distress in cancer patients. Psychooncology 1999;8:451-8.

42. Mansfield CJ, Mitchell J, King DE. The doctor as God's mechanic? Beliefs in the Southeastern United States. Soc Sci Med 2002:54:399-409.

43. Rasinski KA, Kalad YG, Yoon JD, et al. An assessment of US physicians' training in religion, spirituality, and medicine. Med Teach 2011;33:944-5.

44. Sinclair S, Pereira J, Raffin S. A thematic review of the spirituality literature within palliative care. J Palliat Med 2006;9:464-79.

45. Peterman $\mathrm{AH}$, Fitchett G, Brady MJ, et al. Measuring spiritual well-being in people with cancer: the functional assessment of chronic illness therapy-Spiritual Well-being Scale (FACIT-Sp). Ann Behav Med. 2002;24:49-58.

46. Harmon-Jones E, Simon L, Greenberg J, et al. Terror management theory and self-esteem: Evidence that increased self-esteem reduced mortality salience effects. J Pers Soc Psychol 1997;72:24-36.

47. Sinclair S. Impact of death and dying on the personal lives and practices of palliative and hospice care professionals. Can Med Assoc J 2011:183:180-7.

48. Sansó N, Galiana L, Oliver A, et al. Palliative care professionals' inner life: exploring the relationships among awareness, self-care, and compassion satisfaction and fatigue, burnout, and coping with death. J Pain Symptom Manage 2015. http://www.researchgate. net/profile/Enric_Benito/publication/275246056_Accepted manuscript_JPSM_2_(1)/links/553610c60cf20ea35f10fb14.pdf

49. Kuhl D. What dying people want: practical wisdom for the end of life. Cambridge, CA: PublicAffairs, 2003.

50. Selman L, Harding R, Gysels M, et al. The measurement of spirituality in palliative care and the content of tools validated cross-culturally: a systematic review. J Pain Symptom Manage 2011;41:728-53. 